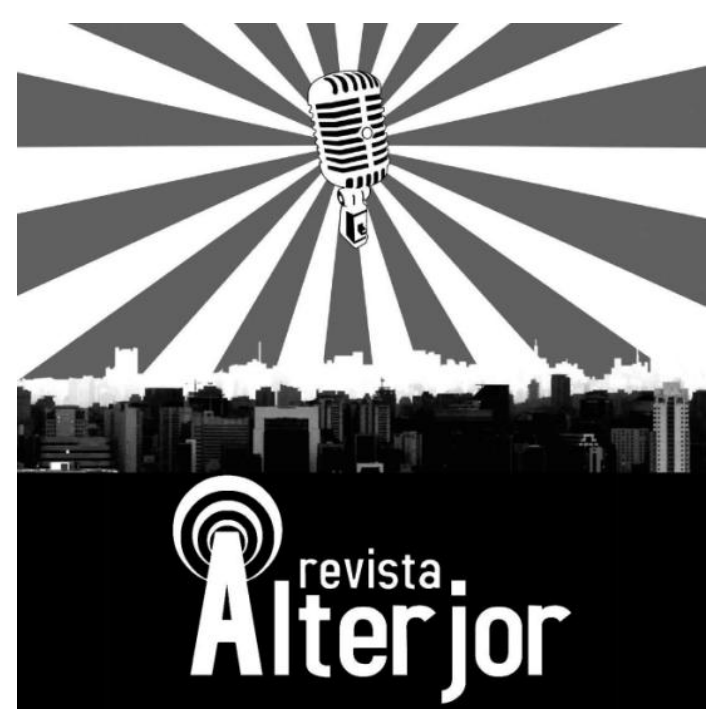

DOSSIê: "Comunicação nas Periferias"

\title{
FIDEL RUIZ: “O 'ILUMINADO’ TEM QUE VIR, MAS COM A MOCHILA MEIO VAZIA PARA TAMBÉM APRENDER COM A GENTE"
}

\author{
Patrícia Sheila Monteiro Paixão Marcos ${ }^{1}$
}

RESUMO: Representante da revista La Garganta Poderosa, uma das principais iniciativas de comunicação popular da Argentina e da América Latina, Fidel Ruiz conta como nasceu esse veículo de jornalismo comunitário, na Villa Zavaleta, em Buenos Aires. Ele fala sobre o empoderamento e as conquistas dos moradores locais a partir da credibilidade conquistada pela revista que hoje, também por intermédio de um espaço na TV, denuncia a violência policial, as falhas do Estado e muitas outras questões vividas pelas comunidades periféricas daquele país. O ativista ainda aborda a importância da integração dos setores populares latino-americanos que vivem as mesmas problemáticas e se reconhecem pela eterna resistência.

PALAVRAS-CHAVE: Comunicação popular. Comunicação comunitária. Comunidade. Entrevista.

ABSTRACT: A member of La Garganta Poderosa magazine, one of the main popular communication initiatives in Argentina and Latin America, Fidel Ruiz tells how this community journalism vehicle was born, at Villa Zavaleta, in Buenos Aires. He talks about residents' empowerment and achievements based on the credibility gained by the magazine, which today, also through a space on TV, denounces police violence, the failings of the State and many other issues experienced by the popular communities of that country. The activist also speaks about the importance of integrating popular Latin American sectors that are experiencing the same problems and are recognized for their eternal resistance.

KEYWORDS: Popular communication. Community communication. Community. Interview.

\footnotetext{
Doutoranda pelo Programa de Pós-Graduação Integração da América Latina (PROLAM/USP) e mestre em Comunicação pela Universidade Metodista de São Paulo (UMESP). Jornalista e professora do curso de Jornalismo da Universidade Presbiteriana Mackenzie e da Universidade São Judas. Patrícia Paixão estuda as iniciativas de comunicação contra-hegemônicas no Brasil e na Argentina e realizou essa entrevista em Buenos Aires, em julho de 2019, como parte das pesquisas para seu doutorado. E-mail: paixao.patricia@uol.com.br.
}

\section{Revista AL TERJOR}

Grupo de Estudos Alterjor: Jornalismo Popular e Alternativo (ECA-USP)

Ano 10 Volume ol Edição 23 Janeiro-Julho de 202l

Avenida Professor Lúcio Martins Rodrig̉ues, 443, Cidade Universitária, São Paulo, CEP: 05508-020 


\section{INTRODUÇÃO}

Os ex-presidentes Luiz Inácio Lula da Silva, Dilma Vana Rousseff, Juan Evo Morales Ayma e José Alberto Mujica Cordano. O linguista Noam Chomsky. Os jogadores Diego Armando Maradona Franco e Lionel Andrés Messi. Os atores Francesc Orella (da série Merlí) e Rodrigo de la Serna (de A Casa de Papel). Essas personalidades, normalmente muito procuradas para serem entrevistadas por veículos da mídia hegemônica de todo o mundo, já toparam aparecer com a boca escancarada, exibindo a garganta, na capa de uma revista feita por moradores de uma favela de Buenos Aires. O rosto de uma celebridade com a boca aberta é uma tradição na primeira página de La Garganta Poderosa, publicação da comunidade de Villa Zavaleta, tida hoje como uma das principais iniciativas de comunicação popular da América Latina. Com centenas de milhares de seguidores no Facebook e no Instagram, a revista atingiu uma credibilidade que lhe rendeu um espaço semanal em um dos principais canais de TV argentinos, o C5N. Graças a esse prestígio, hoje os integrantes da publicação são tidos como fonte de referência quando o assunto envolve repressão policial, direitos das comunidades periféricas, violência de gênero e outras questões relacionadas aos direitos humanos. "Tudo o que La Garganta cobre, repercute", diz, com orgulho, Fidel Ruiz.

Fidel esteve presente desde os primeiros momentos de criação da organização $L a$ Poderosa, que deu origem à revista. Tudo começou em 2004, quando ele tinha 9 anos, com partidas de futebol entre meninos e meninas, feitas de maneira despretensiosa em um campinho improvisado dentro da comunidade. A garotada começou a definir suas próprias regras num jogo sem árbitro e sem personalismos. Aos poucos, assuntos para além do esporte começaram a ser discutidos nas rodas de conversa que aconteciam antes de cada pelada. E os pais dos meninos e meninas, além de outros moradores da comunidade, começaram a participar das discussões. Em 2008, a revista surge como forma de apresentar uma contra-narrativa à cobertura preconceituosa e deturpada feita 


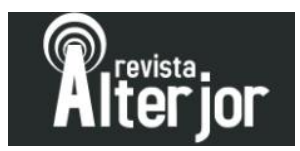

pelos grandes meios de comunicação, que viam a Zavaletta como "uma antessala da morte".

Nesta entrevista, Fidel fala sobre a evolução da organização La Poderosa e sobre as principais problemáticas que a comunidade busca denunciar; questões que possuem muita semelhança com aquelas vividas pelas comunidades brasileiras.

\section{ENTREVISTA}

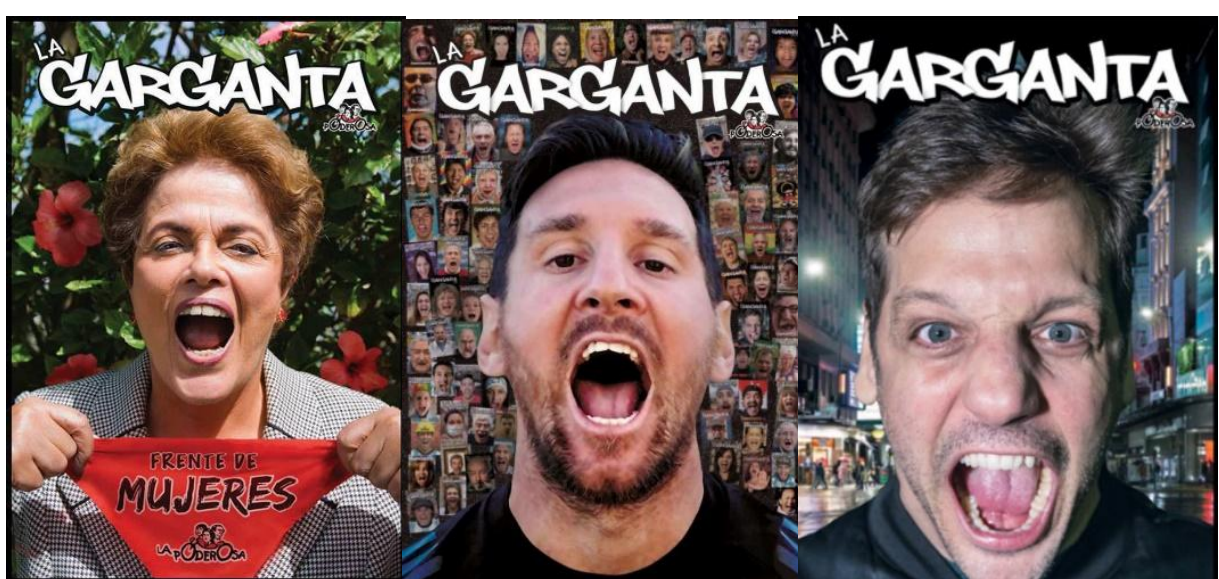

Algumas das capas de La Garganta Poderosa

PATRÍCIA PAIXÃO: Em uma entrevista concedida ao veículo KolectiVOZ Digital, do Equador, você diz que a organização La Poderosa, que mais tarde vai dar origem à revista La Garganta, começou como um grupo de futebol popular, com meninos e meninas da Villa Zavaleta. Pode nos contar sobre esse início?

FIDEL RUIZ: La Poderosa nasceu em 2004 na Villa Zavaleta, que fica a 15 ou 20 minutos de pontos bastante frequentados pelos turistas em Buenos Aires, como o Obelisco. Aqui em Buenos Aires temos essa característica de ter villas [favelas] dentro da cidade. E surgiu com algo que parecia muito incomum, algo que não é habitual na hora que você estrutura uma organização: uma bola de futebol. A primeira coisa foi 


\section{Preiejer}

discutir que nome a gente ia dar para o espaço, porque se a gente chamasse de "futebol villero" já haveria um problema.

PATRÍCIA PAIXÃO: O preconceito?

FIDEL RUIZ: Sim. A denominação villero é pejorativa por causa da forma como os meios de comunicação cobrem as villas. Toda vez que há um problema em matéria de segurança ou do que quer que seja botam a culpa nas villas. Para a comunidade, villero é uma palavra ruim, porque nos acostumamos a ouvir que ser villero representa tudo o que é mau. Então decidimos colocar o nome de La Poderosa em homenagem à moto de $\mathrm{Che}^{2}$. Mas não porque somos uma comunidade guevarista ou marxista, e sim pela ideia de empoderamento, de luta e resistência.

PATRÍCIA PAIXÃO: E como eram essas partidas de futebol que acabaram resultando na criação de uma organização comunitária?

FIDEL RUIZ: Elas aconteciam em um campinho improvisado na comunidade. Eu tinha 9 anos, quando começamos. Muitos de nós jogávamos bola todos os dias. Era uma forma de socialização por causa do futebol. Daí começamos a fazer uma roda de conversas. Um olhava para a cara do outro sem entender nada. "Mas o que é uma roda de conversas? Do que se trata isso?". A molecada só queria jogar bola. Mas nessas rodas a gente discutia a nossas próprias regras. Por exemplo: jogávamos sem árbitro. Foi só depois que a gente entendeu por que resolvemos jogar assim. Em primeiro lugar, porque sempre vinha alguém de fora do bairro, a figura de um "iluminado", dizendo como a

\footnotetext{
${ }^{2}$ Esse foi o nome que Ernesto Che Guevara deu à motocicleta que usou para percorrer a América Latina, ao lado de se amigo Alberto Granado Jiménez. Com ela, o então estudante de Medicina argentino fez a viagem que seria um divisor de águas em sua vida, por mudar sua percepção de mundo ao reconhecer as semelhanças com que os povos latino-americanos eram explorados e injustiçados. É ao longo dessa trajetória por diversas nações irmãs que Che vai se engajar na luta que o tornará um dos maiores líderes da libertação dos povos latino-americanos.
} 


\section{Preiejer}

gente tinha que fazer as coisas. Sempre nos impunham regras, normas que não eram traçadas por nós e com as quais não concordávamos. É comum ver aquele que vem de fora como o cara que tem conhecimento e você, villero, não sabe das coisas. Começamos a discutir que, tudo bem, o "iluminado" tem que vir, claramente a gente precisa e se interessa por ele, mas tem que vir com a mochila meio vazia para também aprender com a gente. Além disso, jogar sem árbitro era uma forma de a gente começar a gerar um processo de diálogo coletivo dentro do nosso território. Começar a discutir até se, por exemplo, o lateral tinha que ser cobrado com a mão ou com o pé, afinal era uma decisão nossa. Depois, a gente passou a se dar conta de que as discussões na roda iam além disso; elas representavam um intercâmbio. "Bom, eu penso isso, você pensa outra coisa". E foi aí que começamos a nos organizar por consenso. A gente não vota, a gente entra em consenso.

PATRÍCIA PAIXÃO: Nunca houve uma estrutura hierárquica entre vocês?

FIDEL RUIZ: Não, não. Era uma discussão. Todo mundo era responsável pela ocupação do espaço. Foi aí também que a gente começou a se dar conta de que havia um espaço. Às vezes acontecia de eu chegar tarde ao treino, ou dos meus companheiros chegarem tarde. Não era porque a gente queria, mas porque tinha chovido naquele dia e a gente estava tirando água das nossas casas, porque nosso piso estava todo inundado. Foi sobre essas coisas que a gente começou a discutir nas rodas de conversa, do porquê a gente chegava tarde. Além disso, entre as regras que a gente estabeleceu estava o que fazer com quem xinga o adversário. Pensávamos, por exemplo, sobre o que fazer com quem chamou o companheiro de "boliviano" ou de "paraguaio". Por que chamar o outro de "paraguaio" se ele tem nome? Começamos a abrir essas e outras discussões.

PATRÍCIA PAIXÃO: De novo a questão do preconceito, né? 


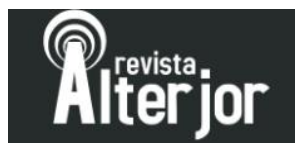

FIDEL RUIZ: Sim, o mesmo preconceito instigado pelos meios de comunicação desde os anos 90. Pós- $2001^{3}$ fica marcado o famoso discurso de que os que vinham "de fora" estavam aqui para roubar a educação, a saúde, nossas casas, e isso acaba gerando esse preconceito. A gente começou a discutir o porquê dos paraguaios e outros imigrantes terem vindo pra cá. Nessa, um dos meninos disse: "Meu pai veio pra cá para conseguir trabalho". E aí começamos a conversar sobre todas essas coisas e também a gerar outras discussões. A primeira regra que a gente combinou é que todo mundo tinha que tomar café da manhã - geralmente chá mate com pão. E então aos 20 meninos e meninas se somaram outros 10, ou seja, já éramos 30. Quando chegou o dia 24 de março ${ }^{4}$ discutimos por que a gente não conhecia a história do nosso bairro. Por que não nos conhecíamos? Por que não aparecem nos registros oficiais os villeros desaparecidos na ditadura? Muita gente se cansava de ficar lá falando uma hora e não começar logo o jogo, mas isso era porque a gente sempre acabava muito envolvido nessas discussões.

PATRÍCIA PAIXÃO: Então a discussão passou do futebol para outras temáticas, de forma bem natural?

FIDEL RUIZ: Sim, porque o ato de criar a roda de conversa gerou diálogo e deu notoriedade para essa molecada que tinha necessidade de falar e não tinha espaço para se juntar e conversar. Eles não podiam falar com suas famílias, porque o pai estava trabalhando e, na estrutura de merda dessa sociedade, a mãe estava $100 \%$ ocupada com a casa. Então, com quem falar? A gente tinha 9, 10 anos e não tinha se dado conta de que estávamos criando uma assembleia. Por exemplo, quando começamos a jogar futebol, a gente percebeu que tinha um poste de luz bem no meio do nosso campinho, com poços nas laterais. Não dava pra jogar bola, porque, se alguém caísse no poço,

\footnotetext{
${ }^{3}$ Em 2001 a Argentina viveu uma grave crise econômica e política. O país anunciou um calote em sua dívida pública, que na época era de cerca de US\$ 100 bilhões. A decisão abalou a confiança dos investidores, afastou empresas estrangeiras e fez o país ter dificuldades para conseguir empréstimos internacionais.

${ }^{4}$ Dia Nacional da Verdade pela Memória e Justiça, feriado argentino para honrar a memória das mais de 30.000 vítimas do Golpe de Estado de 1976, naquele país.
} 


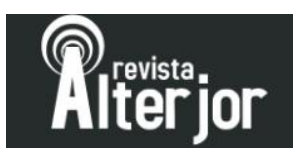

podia se machucar. E ainda por cima o poste de luz não iluminava. Foi aí que começamos o trabalho voluntário. Costumávamos fazer três dias de treino. Então, decidimos que treinaríamos em dois dias e reservaríamos um dia para fazer trabalho voluntário. Foi quando a gente chegou à conclusão que, assim como estávamos ali unidos para resolver problemas da comunidade, também era necessário que nossos pais se juntassem à discussão. Assim foram iniciadas as assembleias populares toda semana. Começava uma nova dinâmica e o espaço se transformava a partir da demanda social, de um poder de luta popular. Em nossa segunda roda de conversa, fizemos a leitura de um conto. Nós não tínhamos acesso aos livros, eles não chegavam até nós, não existiam bibliotecas. Eu levei da biblioteca do colégio três livros: um que era um mapa interativo da cidade, outro da Revolução Francesa e um do Egito. Minha mãe recebia bilhetes da escola alertando que eu tinha roubado livros. E minha vieja [jeito carinhoso de dizer "mãe"] brigava com a escola: "Como é que ele vai roubar os livros? São emprestados!". E assim começamos a afinar as discussões. Cada vez que surgia alguma questão no bairro, a gente criava alternativas, discutia, lia contos.

PATRÍCIA PAIXÃO: Sobre o que eram os contos que vocês liam?

FIDEL RUIZ: Líamos desde a história do Che Guevara aos contos do [Eduardo] Galeano. Líamos de tudo. E no caso dos contos do Che não líamos de uma maneira doutrinária, mas como um jeito de construir nossa história, nosso poder de luta latinoamericana. Porque nessa mesma roda havia paraguaios, bolivianos, peruanos, argentinos.

PATRÍCIA PAIXÃO: É interessante para todos.

FIDEL RUIZ: Sim, e aí começamos a abrir outros espaços como o de educação popular e o de arte. Para pensar uma organização era preciso começar pelas bases puras, 


\section{Ritieior}

que era a juventude, a infância. Discussões maravilhosas aconteciam nas rodas de conversa. Percebemos que estávamos criando um elo entre as gerações. Esses moleques de 9 anos estavam ali discutindo numa roda de apoio popular e era necessário construir um caminho para que eles, quando tivessem 16, 17, estivessem em suas assembleias, debatendo coisas importantes, sendo referências para a comunidade. A juventude lutando faz parte da história do bairro. Há várias pessoas na Zavaleta resistindo há 30, 40 anos, que foi quando começou a se criar todo esse empoderamento de luta que o bairro tem hoje. Temos sempre que criar algo a mais para que a discussão continue. $\mathrm{O}$ bairro resistiu a tudo: às crises econômicas, à ditadura militar... O que tinha de ser feito era valorizar isso e ressignificar a palavra "luta" e a palavra "poder". O que é o poder? O poder não é o que nos alimenta nem é aquilo que os meios de comunicação evangelizam. Foi preciso ressignificar a palavra a partir da organização popular e da construção coletiva. De começar a gerar não consciência, porque isso a comunidade já tem, mas um nível de incentivo, saber do que somos capazes. A comunidade estava cansada da política, porque os políticos mentem o tempo inteiro. Eles vão à villa a cada quatro anos para prometer e depois deixam que nos viremos sozinhos. A gente [ $\mathrm{La}$ Poderosa] fez o caminho inverso, o de não prometer. O que fizemos foi dizer: "Vamos nos organizar!". Sabemos que podemos conquistar mais coisas quando nos unimos.

PATRÍCIA PAIXÃo: É verdade que a Villa Zavaleta surge como uma zona habitacional que deveria ser transitória?

FIDEL RUIZ: Em 2019 a Zavaleta completou 50 anos, ou seja, já são duas gerações vivendo na "transitoriedade", num "núcleo habitacional transitório". O núcleo foi inaugurado em 1969, no governo do ex-presidente Juan Carlos Onganía, um governo militar que mandou as pessoas pra lá com a promessa de moradia. Os moradores não poderiam transformar essas casas em habitação permanente, porque o lugar era transitório. E quem se mudava pra lá tinha que pagar por essas casas, muito precárias. Depois, na época da ditadura, em 1976, houve outras promessas para as villas, que não 


\section{Ritieior}

foram cumpridas. Todos esses anos foram só promessas, promessas e promessas. Foi da resistência do bairro, ocupando edifícios do governo, para que alguém resolvesse a situação da villa, que há 12 anos um quarto [das habitações populares] foi regularizado. Eles comeram - aqui na Argentina a gente usa esse termo para falar que roubaram - o dinheiro da continuação das obras de regularização da Zavaleta e hoje faz 12 anos que ela está assim, com três quartos do bairro sem moradia digna. E é loucura, porque Zavaleta não é uma villa, é um bairro criado pelo Estado. E é um bairro esquecido pelo Estado. Há companheiras nossas, como a Alejandra Díaz, que é histórica no bairro e mora nele há 50 anos. Ela tem até certificado da casa, da propriedade. Ela se mudou pra lá muito criança e escutou um monte de promessas.

PATRÍCIA PAIXÃo: Que situação!

FIDEL RUIZ: Pois é. E toda vez que ela fala da Zavaleta, ela mostra seu certificado e não adianta nada. Por isso que quem é de Zavaleta se irrita muito quando chamam o bairro de villa. Não é porque as villas sejam ruins, mas é porque a Zavaleta é um bairro criado pelo Estado. Vivemos lutando pela regularização da Zavaleta como lutamos pela regularização de todos os bairros. E o bairro está se organizando. Fazemos muitos murais denunciando a falta de políticas públicas e de urbanização. Isso porque quando a gente fala de urbanização não falamos só de um teto e de quatro paredes. Urbanização é a garantia de tudo: das condições habitacionais, das condições ambientais, da saúde...

PATRÍCIA PAIXÃO: Sim, porque o conceito de moradia digna não é só sobre ter um lugar seguro que nos abrigue, mas um teto que seja próximo de aparelhos de educação, saúde, cultura. No Brasil, em muitos territórios periféricos as mães não têm onde deixar seus filhos para irem trabalhar.

Revista AL TERJOR

Grupo de Estudos Alterjor:Jornalismo Popular e Alternativo (ECA-USP)

Ano 10 Volume Ol Edição 23 Janeiro-Junho de 202l

Avenida Professor Lúcio Martins Rodrig̉ues, 443, Cidade Universitária, São Paulo, CEP: 05508-020 


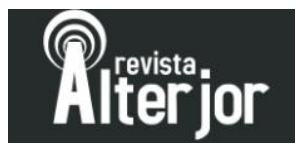

FIDEL RUIZ: Sim, claramente. Quando falam de urbanização, falam somente de uma moradia e para gente isso não é tudo. É preciso que os moradores tenham um campinho onde jogar bola, uma rua, uma praça, tudo o que garanta uma vida digna. É muito simplista falar de urbanização, quando ela se resume à moradia. A gente quer tudo, porque é um direito. O 14 [artigo da Constituição Argentina] fala justamente sobre isso. Sempre me lembro de uma das rodas de conversa popular quando foi levantada a questão: "O que é a liberdade?". Aí as pessoas começaram a falar: "Liberdade é falar, é caminhar, é isso e é aquilo". E um dos nossos companheirinhos disse: "Também é comer”. E aquilo foi muito sábio. E liberdade também é urbanização. Faz 50 anos que estamos lutando. Por sorte, as gerações não deixaram de lutar e transmitiram toda essa batalha para os mais jovens. Cabe aos de hoje garantir esse nível de consciência e de empoderamento para as gerações que seguem, para que elas não abandonem a luta.

PATRÍCIA PAIXÃO: E foi nesse contexto de consciência e empoderamento que surgiu a revista La Garganta?

FIDEL RUIZ: Sim. Em 2008, decidimos construir uma praça, que se chama Praça Kevin. Ela foi feita na comunidade com trabalho voluntário, todos os dias muitas pessoas ajudavam. Em 2009, um canal de televisão daqui de Buenos Aires fez uma reportagem que se chamava "Zavaleta na antessala da morte". São imagens de merda, tudo muito macabro. A matéria mostrava pessoas morando nas ruas, carros desmanchados, um outro grupo de pessoas que pedia esmola nas casas. Dizia que na Zavaleta viviam piranhas, que é como chamam aqui essas pessoas que cometem assaltos nas ruas, pegando, por exemplo, o celular das outras. A Zavaleta está rodeada por duas avenidas: uma que passa por dentro da comunidade, que é a Avenida General Iriarte, e outra que passa por fora, que se chama Amancio Alcorta. Então, diziam que nesta Av. Alcorta as pessoas da villa iam roubar e depois entravam no bairro para se esconder. Eram minutos e mais minutos dedicados a fazer da gente uns merdas. Usavam imagens de um outro documentário, feito por uma organização que se chamava Vientos 


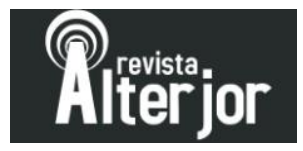

del Sur. Essa organização era formada por uma molecada que tinha se recuperado das drogas e que resolveu fazer um documentário para divulgar o trabalho que a comunidade fazia. Primeiro, mostravam as pessoas que pediam nas casas que, na verdade, era gente que pedia para uma cooperativa - eles iam de porta em porta, pediam por resíduos e os vizinhos colaboravam [com dinheiro] se queriam. Com essa grana, eles levavam comida para quem ainda morava na rua. Sobre os carros desmontados, na verdade, eles [moradores de Zavaleta] mudavam os carros de lugar, faziam reclamações para o Governo da Cidade para que alguém viesse retirá-los, e os levavam para fora do bairro para que as crianças não entrassem neles, porque elas poderiam se machucar. Esses carros eram um ponto de infecção no bairro, estavam contaminados. Esse trampo lindo que esses moleques [que gravaram o documentário sobre as ações dos moradores] fizeram ganhou até um prêmio num festival e por isso gerou repercussão em outros meios de comunicação. E aí o que o canal de TV foi lá e fez? Pegou parte desse documentário lindo que esses moleques tinham feito, distorceu informações e produziu a matéria "Zavaleta na antessala da morte". Por conta da repercussão negativa dessa reportagem, vários moradores da comunidade ficaram sem trabalho. Os ônibus que circulavam pelo bairro pararam de passar durante a noite. Muitas crianças sofriam discriminação nas escolas, eram chamados de chorros [forma pejorativa para "ladrão"]. Por causa disso, a gente fez uma assembleia com toda comunidade na Praça Kevin e decidimos fazer uma intervenção na porta do canal de TV. Foi o bairro todo pra lá para mostrar aquilo que o canal tinha esquecido: o refeitório comunitário, a rua popular, todos os espaços lindos que tínhamos. Tinha até um cartaz com "Eu conheci minha primeira namorada na Zavaleta" e outros desse tipo. Claro que não veio nenhum meio de comunicação cobrir essa intervenção. Aí dissemos: bom, alguma coisa a gente tem que fazer para intervir, porque senão eles vão continuar falando um monte de porcaria do bairro. Foi aí que começamos a pensar em criar um meio de comunicação.

PATRÍCIA PAIXÃO: Para ter uma contra comunicação? 


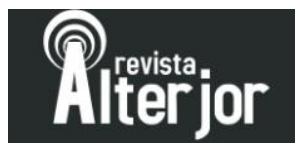

FIDEL RUIZ: Sim! E aí começamos a discutir, porque ninguém tinha experiência na área de comunicação, a não ser um de nossos companheiros que era o único que tinha ferramentas técnicas para dizer que rumo deveríamos tomar. Já os outros não tinham nada. Não sabíamos por onde diabos começar. Pensamos: "Bom, vamos fazer uma revista! Podemos pôr essa notícia aqui, essa outra lá". Só que aí surgiu outra discussão genial: Como a gente ia fazer isso? Porque se a gente divulgasse só aqui na vizinhança, não ia adiantar nada, pois todos já sabiam o que acontecia por aqui. Então pensamos que era preciso fazer algo para que a revista chamasse a atenção. Porque, lamentavelmente, não podemos escapar dessa lógica de consumo. Essa sociedade de merda faz com que as pessoas consumam aquilo que vai chamar a atenção. Não podíamos colocar um morador na capa, porque desse jeito ninguém ia comprar, nem no bairro iam ler. Pensamos: "Bom, então, vamos pôr famosos". Ninguém gostava da ideia de colocar um famoso na capa, porque ele ia ofuscar todo o trabalho da comunidade, todo mundo ia falar do famoso em vez de falar do bairro. Aí um companheiro disse: "Bom, então que ele [o famoso] apareça gritando e na contracapa saia uma mensagem do bairro". E aí logo pensamos que o título poderia ser La Garganta. E outro deu a ideia: "A gente pode falar de algum problema central, criticar alguma coisa que aconteceu, ou divulgar a inauguração de um centro cultural ou ainda publicar uma mensagem de conjuntura, daquilo que queremos dizer". Fomos realizando oficinas de comunicação, de fotografia, de ilustração, de redação. Assim nasceu La Garganta, de um cansaço comunicacional.

PATRÍCIA PAIXÃO: Qual é a periodicidade da revista?

FIDEL RUIZ: Mensal. Mensalmente nós abarcamos todas as frentes. Cobrimos a parte de esportes, de cultura. Em 2011 nasceram os eixos de direitos humanos e de abuso policial, que a gente chama de "repressão estatal". A gente já tinha sofrido com isso. Muitos dos nossos meninos, companheiros de La Garganta, enfrentaram o abuso policial. A gente teve, da nossa equipezinha, do nosso primeiro contato com o futebol popular, três mortos pela polícia num só ano. Não tínhamos onde denunciar o gatilho 
fácil [expressão usada para designar a letalidade policial], não tínhamos a estrutura que La Garganta tem hoje. Em 7 de setembro de 2013, aconteceu o caso Kevin Molina, um menino de 9 anos que morreu numa zona invadida pela Força de Segurança. Foram cinco disparos numa casinha que ficava a 50 metros da gendarmería [guarda análoga à Polícia Militar no Brasil] e a 150 metros de outra Força Nacional. E ninguém escutou nada. Bom, foi aí que a gente disse "chega!". Começamos a pensar sobre as ferramentas do abuso policial e sobre um controle popular da atuação das Forças de Segurança.

PATRÍCIA PAIXÃo: Controlam como? Observando?

FIDEL RUIZ: Observando sim, mas temos hoje uma estrutura maior, embora seja bem precária, porque não temos recursos para sustentá-la. Uma boa estrutura requer muitos advogados, psicólogos, tudo isso. Além de denunciar operacionalmente as Forças de Segurança, precisamos de proteção. Precisamos de outras ferramentas. Quando pensamos em fazer a revista, ficamos com medo, porque era a gente que estava monitorando as forças que podem nos descer o cacete. Fazer a revista era uma forma de controlar a força com a qual eu tenho que conviver todos os dias da minha vida, aquela que passa na porta da minha casa todas as tardes. Assim como a gente via em La Garganta uma obrigação comunicacional histórica, de nossa responsabilidade como militantes territoriais, tínhamos também que criá-la para interpelar os de fora. Aquilo que acontece nos bairros tinha que chegar do lado de fora. Tanto a violência policial como outras pautas importantes ligadas aos Direitos Humanos, como as questões relativas à violência de gênero. Principalmente a partir de 2015, quando foi a primeira marcha de Ni Una Menos ${ }^{5}$, a temática de gênero ganhou força na comunidade. Toda violência sofrida pelas companheiras passou a ser mais debatida e elas se organizaram nesse sentido. Hoje, no bairro e aqui na cidade de Buenos Aires existem duas Casas da Mulher e dissidências, que são lugares em que o espaço de reparação, de educação e de

\footnotetext{
${ }^{5}$ Mobilização feminista contra a violência de gênero, que ocorreu pela primeira vez em 2015 na Argentina, envolvendo mulheres de outros países latino-americanos.
} 
saúde gera proteção para as mulheres. As moradoras da Villa 31 e da Villa 21-24 já têm os seus lugares e sabem onde podem ir quando precisarem.

PATRÍCIA PAIXÃO: Em minhas pesquisas sobre La Poderosa eu li que desde o início as mulheres tiveram poder de voz. As partidas de futebol, que geraram a organização, contavam com meninas e meninos jogando juntos, certo?

FIDEL RUIZ: Sempre foi assim. O que ocorre é que hoje a gente tem um plano de gênero. Muitas companheiras incríveis entraram nessa luta. A juventude em nossos espaços de gênero é maravilhosa. Tudo isso nasceu com o futebol lá em 2004 com meninas e meninos jogando juntos, coisa que a gente pensou como uma maneira de derrotar essa questão retrógrada que tem o futebol, desde suas negociações até a sua forma de olhar para a sociedade. Não só o machismo, mas o "ato de separar", o personalismo puro, sabe? A gente [em Zavaleta] busca fazer com que os meninos e as meninas estejam no mesmo campo, o que também é criar uma questão de coletividade, de abandonar o personalismo de merda que nos acostumaram a construir nas pessoas. Esse sistema social vai além do bairro, é uma questão generalizada que mata a coletividade. O futebol permite unir, permite construir, gerar uma discussão que vai além de "você tem mais saberes do que eu". Isso de juntar meninas e meninos no mesmo campo é uma verdadeira construção coletiva. Porque se separamos meninos de um lado e meninas do outro não estamos gerando nada. Claramente custa muito pôr tudo isso em prática, não é que seja tudo lindo. Porque sempre que recrudesce a questão social, econômica e política nesse país, mais se vê violência nos bairros. E mais: temos que começar a colocar essa discussão em todos os espaços. Hoje temos um espaço que nos permite gerar essas ferramentas. Além disso, La Garganta nos deu outra possibilidade que é a de que villeras e villeros falem nos meios de comunicação. Ganhamos parte da batalha educacional ocupando um segmento no C5N, um canal de televisão que temos aqui em Buenos Aires. Conquistamos esse espaço por causa da revista. Todas as segundas-feiras neste canal é possível ver o ponto de vista de $L a$ 
Poderosa, denunciando casos e mostrando a realidade que outros meios não mostram. Hoje, tudo o que La Garganta cobre, repercute. E isso aconteceu por causa de tudo isso que eu estou te dizendo: por causa do plano de gênero, de um espaço para o esporte, do controle popular. Hoje os grandes meios de comunicação repercutem o nosso trabalho. Quando há algum problema habitacional, de gênero ou de repressão estatal, chamam La Garganta para discutir.

PATRÍCIA PAIXÃO: No Brasil, o ativista, jornalista e professor Doutor da Universidade de São Paulo (USP), Denis de Oliveira - uma das principais referências do movimento negro, debate o conceito de “jornalismo emancipatório". Apoiado nas teorias do educador Paulo Freire e do jornalista Adelmo Genro Filho, Dennis defende que para que a comunicação seja de fato libertadora ela precisa partir da experiência do oprimido, daqueles que de fato vivenciam as problemáticas a serem retratadas. Podemos considerar La Garganta como uma experiência de comunicação emancipatória?

FIDEL RUIZ: Sim, sim. Os meios comunitários são claramente assim. Nós também dizemos isso por aqui. La Garganta não seria La Garganta se não fosse um meio comunitário. Muitas vezes subestimam os meios comunitários por causa da qualidade, que não perde nada para os meios tradicionais e que é uma maneira de fazer jornalismo deste lado, não do outro. Não de um estúdio de televisão, mas estando ao lado do povo. A gente valoriza muito as experiências comunitárias. Se não fosse pelos meios de comunicação construídos pela comunidade a gente não conseguiria esse nível de repercussão que temos hoje. Quando a ex-ministra de Segurança Pública, Patricia Bullrich [do governo do ex-presidente Mauricio Macri], disse numa coletiva de imprensa que La Garganta mentia, a notícia saiu em todos os meios comunitários, todos nos apoiaram e nos deram força. O que a gente pode discutir é como cada um faz seu jornalismo. O trabalho feito pelos meios comunitários muitas vezes é incrível. A gente tinha a necessidade de fazer um jornalismo criado no bairro basicamente, porque a gente é uma organização que nasce no nosso território. A gente sempre indica o Rodolfo 


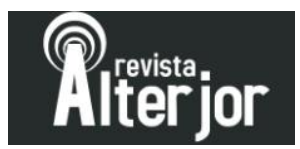

Walsh $^{6}$ como referência, porque ele defendia a ideia de um jornal semanal villero. A gente valoriza e precisa dessas experiências. Entendemos que é preciso mudar o jornalismo a partir do villero, incluindo o villero na discussão. Quando a gente olhava para os jornalistas argentinos nos meios tradicionais víamos gente alta, baixa, gorda, magra, de sagitário, de escorpião, da torcida do Boca Juniors, da torcida do River Plate, mas não tinha nenhum villero. E não é porque não existam jornalistas villeros, mas é que nunca foi dado espaço para eles. Nunca houve espaço. Em La Garganta a gente se vê como tendo uma responsabilidade histórica, a de colocar os villeros na discussão e de não nos fecharmos no próprio bairro. A gente fez um meio para interpelar a sociedade que não vive no bairro. Sempre usam a palavra "consciência" quando se referem a nós, como se não tivéssemos educação, como se não fossemos críticos. Mas quando vemos pessoas que pensam que nós somos daquele jeito que foi mostrado na reportagem "Zavaleta como antessala da morte", vemos que a falta de consciência, na verdade, é dessas pessoas. Mas não adianta ficar bravo com os alienados, temos que trazê-los para o nosso lado.

PATRÍCIA PAIXÃO: E para isso existe La Garganta?

FIDEL RUIZ: Sim. Colocamos famosos na capa para gerarmos visibilidade, para despertarmos a consciência e interpelarmos aqueles que não conhecem o nosso bairro. Pra gente mudar a realidade, gerar justiça social, só estando do mesmo lado. Não adianta nos irritarmos com quem diz que somos maus. Comunicação é isso: fazer com que os outros vejam um outro ponto de vista, para enxergar a verdadeira realidade. Quando pensamos na comunicação, pensamos em, a partir do lado de cá, começar a fechar as fissuras sociais.

PATRÍCIA PAIXÃO: Vocês têm vínculo com alguma organização política?

\footnotetext{
${ }^{6}$ Jornalista e ativista argentino, que militou nas organizações guerrilheiras FAP (Fuerzas Armadas Peronistas) e Montoneros. É uma das vítimas da ditadura argentina.
} 
FIDEL RUIZ: Nossa organização é apartidária. E não é porque a estrutura partidária seja má. Nós falamos com todo mundo, temos vínculos com todos os companheiros que estão em partidos políticos de esquerda, por todos os lados. Temos também que ter outros vínculos além desses. Porque o que nós temos que gerar primeiro é a consciência de base e esse processo não é tocado pra aumentar os votos de esquerda. É primeiro para gerar uma mudança social a partir do nosso lado. A gente é apartidário nesse sentido, porque reivindicamos e valorizamos o nosso território, nossa comunidade. Claro que nos alinhamos com as forças progressistas. E sabemos que hoje, se a gente concorresse às eleições, isso significaria "roubar" 20 mil votos da esquerda.

PATRÍCIA PAIXÃO: Para finalizar a nossa conversa, gostaria que você falasse sobre como avalia a integração entre os meios de comunicação populares latino-americanos.

FIDEL RUIZ: Isso é muito, muito importante. Porque quando alguém se propõe a observar a realidade chilena, a uruguaia, a brasileira, a colombiana e a de todos os países da região vê o mesmo cenário em todas as nações. Então, é necessário entender que estamos vivendo as mesmas injustiças e que estamos lutando pelas mesmas coisas. Argentina, Brasil, Colômbia, Equador... não seríamos nada sem uma resistência. Os inimigos são do mesmo sistema, os mesmos planos econômicos e políticos. Sofremos todos a mesma merda, a mesma violência, os mesmos preconceitos, e entendemos que hoje temos que estar todos juntos. Nos impuseram fronteiras para que a gente fosse extinto, mas todos moramos num mesmo eixo. Todos estamos sendo violentados há 527 anos. Todos viemos de um contexto de violência, mas também de uma mesma resistência. Na verdade, é um mesmo povo resistindo. Acho que a gente pode ganhar essa batalha. Temos que ver como. Temos que começar a discussão e também sermos conscientes de que estamos todos na mesma. Digo isso por experiência própria e por meus vizinhos dos bairros. Muitas vezes nos sentimos solitários, porque a luta não é nada fácil. Você cai mais do que se levanta. Mas quando temos a oportunidade de 


\section{Retiejior}

observar outros países, a gente se dá conta de que não estamos sozinhos, de que todos nós que somos oprimidos estamos resistindo. 